\title{
Fundamental Study of Oscillations in the Nigerian Power System
}

This paper was downloaded from TechRxiv (https://www.techrxiv.org).

LICENSE

CC BY 4.0

SUBMISSION DATE / POSTED DATE

28-07-2021 / 02-08-2021

CITATION

UGWUANYI, Nnaemeka Sunday; Uma, Uma Uzubi; Ekwue, Arthur Obiora (2021): Fundamental Study of Oscillations in the Nigerian Power System. TechRxiv. Preprint. https://doi.org/10.36227/techrxiv.15066915.v1

DOI

10.36227/techrxiv.15066915.v1 


\title{
Fundamental Study of Oscillations in the Nigerian Power System
}

\author{
N. S. Ugwuanyi, U. U Uma, A. O. Ekwue
}

\begin{abstract}
The power systems in developing countries are usually stressed and operated near their stability limits. Consequently, accurate sources of oscillations and their controls can present a challenge. This paper reports a comprehensive study of the oscillations in the Nigerian 48-bus power system. The dominant modes, sensitive locations for faults, and the most responsible generators were identified by modal analysis. Uniquely, the potential for nonlinear modal interaction of these modes was carefully investigated. The low-frequency modes identified are $1 \mathrm{~Hz}, 1.14 \mathrm{~Hz}$, and $1.37 \mathrm{~Hz}$, and they are associated mainly with the generators at Kainji, Afam, and Delta power stations. The results indicate the existence of inter-area phenomena and nonlinear modal interactions among these modes. Also, the analysis revealed that the generator at the Kainji power station is most affected by the nonlinear interactions.
\end{abstract}

Index Terms-Electromechanical oscillation, modal analysis, nonlinear modal interactions, Nigerian grid, power system dynamics.

\section{INTRODUCTION}

The power system requires precise regulation to function effectively. Oscillation management can be challenging in most developing nations owing to inadequately damped lowfrequency oscillations caused by numerous lengthy transmission lines and system overloading. The nature and origins of these oscillations are not always apparent. For controls, such as tuning of power system stabiliser (PSS) and setting of automatic voltage regulator (AVR), understanding the structure of the power system is very useful. The modal analysis is commonly used to understand the power system structure and to design its controls [1]-[4]. The modal analysis uses eigenvalues and eigenvectors to describe the fundamental oscillation frequencies and oscillation patterns.

One of the main challenges of the power system is the lowfrequency electromechanical oscillations associated mainly with the internal angles and the rotor speeds of the generators. These low-frequency oscillations are well known in various power systems, as are all generators responsible for them. In most developing countries, adequate characterisation of the electromechanical oscillations is lacking, perhaps due to the

N. S. Ugwuanyi is with Univ. Lille, Arts et Metiers Institute of Technology, Centrale Lille, Junia, ULR 2697 - L2EP, F-59000 Lille, France, and also with Department of Electrical/Electronic Engineering, Alex Ekwueme Federal University, P.M.B. 1010, Abakaliki 480214, Nigeria (e-mail: nnaemeka.ugwuanyi@univ-lille.fr

A. O. Ekwue is with Department of Electrical Engineering/ACESPED University of Nigeria Nsukka Nsukka, Nigeria (e-mail: arthur.ekwue@unn.edu.ng)

U. U. Uma is with Department of Electrical/Electronic Engineering, Alex Ekwueme Federal University, P.M.B. 1010, Abakaliki 480214, Nigeria (email: gbogbonna@yahoo.co.uk) continuously changing network structure or inadequate and unreliable dynamic generator data. Some of the generating units in developing countries are either scrapped or out of service due to the damaged exciter, generator bearing problems, rotor balancing and labyrinth seal problem, tripping on $\mathrm{AC}$ failure and system instability or tripping on low gas pressure, fatal fire outbreak, compressor blade failure, e.t.c. Some grid stations are stressed due to frequent shutdowns from transmission line faults. There are usually no area control centres in some operating points, but they have radio communication facilities between them. These centres are supposed to link to a National Control Centre via a Mains transmission station. Communication during peaking off and the efficient coordination of load shedding strategies are common problems in developing nations. The lack of adequate telecommunications equipment makes the dissemination of operational information rather challenging. The proper characterisation of oscillation modes is crucial, especially now that the penetration of power electronics converters into the grid has been found to lead to oscillation modes akin to low-frequency electromechanical ones [5]. Recent studies highlight the increasing interest in the high penetration of renewable energies and, of course, the accompanying power electronics into the Nigerian power system [6], [7].

Like other developing nations, Nigeria's grid is constantly expanding with new transmission lines and generators. Since power systems' low-frequency oscillations are usually a result of electromechanical coupling between the transmission network and generators, when the network is expanded, appropriate studies become necessary to characterise the oscillations. A comprehensive study of the oscillations in the Nigerian power system is missing, despite its importance. Most modal analyses on the Nigerian power system focus on voltage stability (see, for examples, [8], [9]). In the past, a few research on the oscillations in the Nigerian electricity system has been published. A review of the current literature, on the other hand, will soon reveal gaps to fill. The authors in [10] performed modal analysis on a 40-bus Nigerian network, where the system's stability was investigated subject to load increase on the generators. The authors identified the lowfrequency oscillations with frequencies $0.916 \mathrm{~Hz}, 1.102 \mathrm{~Hz}$, and $1.142 \mathrm{~Hz}$ and applied the AVR to improve the system's stability. The $0.916 \mathrm{~Hz}$ corresponds to an inter-area oscillation in which the two areas of the network swing against each other. The authors in [11] used PSS to damp the electromechanical oscillations in the Nigerian power systems. Reference [12] reported a modal analysis of the Nigerian power system with wind, solar and small-hydro sources incorporated. Several 
studies, including short circuit analysis and harmonic analysis, were also reported. The authors presented some nice plots, but the characterisation of the oscillations and interpretations are unclear. In [13], the authors used the Heffron-Phillips Model technique to extract the eigenvalues in the Nigerian power system under different loadings. The low-frequency electromechanical oscillations identified (for $80 \%$ loading) are similar to those reported in [10]. The authors proposed using FACTS devices to reinforce transmission lines and reduce oscillations. Nwohu [14], through time-domain simulation, demonstrated the effectiveness of the unified power flow controller (UPFC) in damping the low-frequency oscillations in the Nigerian power system. Ambafi et al. [15] evaluated the efficiency of PSS and the Static Synchronous Compensator (STATCOM) in damping the oscillation of a North-Central Power Network of Nigeria Grid System and concluded that STATCOM is the best option. However, because several generators in the Nigerian grid are in the south, a more realistic approach that considers northern and southern generators should be studied. Most of the previous studies reported in the literature are based on time-domain simulations to demonstrate the impact on power system dynamics. Though time-domain studies provide a virtual understanding of the dynamic behaviour of power systems, they are incapable of identifying and quantifying the causes and nature of interactions as detailed eigenvalue analyses do. Modal analysis, therefore, compliments timedomain simulations.

From the review, one can conclude that some crucial information such as the generators responsible for the oscillations, the generators' swinging patterns when these oscillation modes are excited, probable disturbance locations where the excitation of these modes are susceptible, e.t.c., are not yet reported in detail. It is important to emphasize that accurate and precise swinging patterns are vital to islanding the generators during faults. Furthermore, the existing literature failed to show how the critical modes structurally affect the system dynamics. This work addresses these missing details.

The current paper is an expansion of the investigations carried out in [16]. The major new contributions are as follows:

- Investigation of potential nonlinear interactions among the low-frequency modes. This valuable information does not exist in the previous works, whereas this paper provides practical hints in that specific direction.

- The nonlinear mode-in-states participation factors are provided in addition to the conventional mode-in-states participation factors.

- The sensitive generator to the influence of nonlinear modal interactions is identified in the Nigerian grid.

The remainder of this paper is organised as follows: Section II provides a concise theory of modal analysis. In this section, the criterion for mode dominance and modal interactions are explained. Section IIII briefly describes the Nigerian 48-bus power system. Section IV] is dedicated to detailed numerical simulations. Section $\mathrm{V}$ concludes the article and suggests possible future works.

\section{Modal Analysis Theory}

The dynamical behaviour of power systems can be represented by differential-algebraic equation (DAE):

$$
\begin{aligned}
\dot{\mathbf{X}} & =\mathbf{f}(\mathbf{X}, \mathbf{u}), \\
\mathbf{0} & =\mathbf{g}(\mathbf{X}, \mathbf{u}) .
\end{aligned}
$$

In (1), $\mathbf{X}$ is a vector of the state variables and $\mathbf{u}$ is a vector of input. A linear model is obtained by linearising (1) around an operating point, usually performed in the neighbourhood of a stable equilibrium point (SEP).

Let $\mathbf{X}_{\mathbf{0}}, \mathbf{u}_{\mathbf{0}}$ be the initial state vector and the input vector respectively, which correspond to the equilibrium point, then, $\mathbf{X}\left(\mathbf{X}_{\mathbf{0}}, \mathbf{u}_{\mathbf{0}}\right)$ is the solution of $(1)$ with $\dot{\mathbf{X}}=\mathbf{0}$. For small perturbation, the new states and inputs are denoted as $\mathbf{X}=\mathbf{X}_{\mathbf{0}}+\Delta \mathbf{X}, \mathbf{u}=\mathbf{u}_{\mathbf{0}}+\Delta \mathbf{u}$, where $\Delta$ stands for increment. After putting the algebraic equations into the differential ones, the linear model is given by

$$
\Delta \dot{\mathbf{X}}=\mathbf{A} \Delta \mathbf{X}+\mathbf{B} \Delta \mathbf{u}
$$

where the Jacobians (i.e. 1st-order terms of Taylor expansion), evaluated at the SEP are $\mathbf{A}=\frac{\partial \mathbf{f}}{\partial \mathbf{X}} \mid \mathbf{x}_{\mathbf{0}}, \mathbf{u}_{0}$ and $\mathbf{B}=\frac{\partial \mathbf{f}}{\partial \mathbf{u}} \mid \mathbf{x}_{\mathbf{0}}, \mathbf{u}_{0}$.

Under the free motion, the system (2) can be written as

$$
\dot{\mathbf{x}}=\mathbf{A x},
$$

where $\mathbf{x}=\Delta \mathbf{X}$. The eigenvalues and eigenvectors are computed from the state matrix, A, by solving the following eigenvalue problem $(\mathbf{A}-\lambda \mathbf{I}) \mathbf{U}=\mathbf{0}$, where $\mathbf{I}$ is an identity matrix, $\mathbf{U}$, the right eigenvector matrix with each column corresponding to one eigenvalue $\lambda_{i}$ of the system, The left eigenvector matrix $\mathbf{V}$ is determined by solving $\mathbf{V A}=\lambda \mathbf{V}$, where each row of $\mathbf{V}$ corresponds to an eigenvalue.

Cross-couplings between state variables are eliminated by converting the linear model to Jordan form using a linear transformation

$$
\mathbf{x}=\mathbf{U y},
$$

where $\mathbf{y}$ is the vector of the Jordan variables.

Substituting (4) into (3) and pre-multiplying by the left eigenvector matrix yields

$$
\dot{\mathbf{y}}=\boldsymbol{\Lambda} \boldsymbol{y},
$$

where $\boldsymbol{\Lambda}=\boldsymbol{V} \boldsymbol{A} \boldsymbol{U}$ is a diagonal matrix with the eigenvalues on the diagonal. Since the system is now decoupled, each element of $\mathbf{y}$ corresponds to a particular eigenvalue. Hence, the solution of (5) for the $j$ th Jordan form variable can be written as

$$
y_{j}(t)=y_{j 0} e^{\lambda_{j} t}
$$

where $y_{j 0}$ is the $j$ th initial condition in the Jordan form coordinate system. The closed-form linear solution in the original generator states for an $N$-differential system is obtained by using the transformation in (4) as

$$
x_{i}(t)=\sum_{j=1}^{N} u_{i j} y_{j 0} e^{\lambda_{j} t} \quad \forall i, j=1,2, \ldots, N,
$$

where $u_{i j}$ is the element in the $i$ th row and $j$ th column of the right eigenvector $\mathbf{U}$. 
If higher-order terms are considered in the linearisation, say order 2, a specific transformation [17]-[19] is applied, in addition to the linear transformation, and the solution is obtained in another new coordinate. At last, the solution will be of the form:

$$
x_{i}(t)=\sum_{j=1}^{N} \mu_{1_{i j}} e^{\lambda_{j} t}+\sum_{k=1}^{N} \sum_{l=1}^{N} \mu_{2_{i k l}} e^{\left(\lambda_{k}+\lambda_{l}\right) t},
$$

where $\mu_{1_{i j}}=u_{i j} z_{j_{0}}, \mu_{2_{i k l}}=z_{k_{0}} z_{l_{0}} \sum_{j=1}^{N} u_{i j} h 2_{j k l}$, and $z_{0}$ is the initial condition in the new coordinate and $h 2$ is a parameter of the transformation. The details of the transformation leading to (8) overshoot the mark of the present work. Interested readers can please refer to [17], [18]. However, important developments from (8) used in this work are presented. The reader is encouraged to understand from (8) that including higher-order terms will help to explain not only the effect of a single eigenvalue on the state variable but also the effects of the combinations of these single eigenvalues. These combinations $\left(\lambda_{k}+\lambda_{l}\right)$ are referred to as modal interactions. The magnitude $\mu_{2}$ will give information into the interactions of the critical modes.

\section{A. Mode-in-state participation factors}

The participation factors represent the size of the modal oscillations in a state when only that state is perturbed. It is an essential quantity in designing power system control. A participation factor is defined with left and right eigenvectors as

$$
P_{k i}=v_{k i} u_{k i}
$$

where $v_{k i}$ and $u_{k i}$ denote the $k$ th components of the eigenvectors $v_{i}$ and $u_{i}$, respectively. The participation factor represents the measure of the participation of the state variable $x_{k}$ in the $i$ th mode.

If the second-order terms are included, a nonlinear participation factor can equally be defined as [17], [20].

$$
\begin{aligned}
& P_{n l_{k l}}^{i}=u 2_{i k l}\left(v_{k i}+v 2_{k i i}\right)\left(v_{l i}+v 2_{l i i}\right), \\
& v_{j i}+v 2_{j i i}=v_{j i}-\sum_{k=1}^{N} \sum_{l=1}^{N} h 2_{j k l} v_{k i} v_{l i} .
\end{aligned}
$$

\section{B. The criterion for determining the dominant modes}

In the tuning and design of controls, the question of which modes dominate the system response is crucial. A measure of the size of mode $j$ in the overall system response is needed. From (7) the contribution of mode $j$ to the oscillations of generator state $i$ for a given disturbance can be seen more clearly if we re-write in compact form as follows:

$$
x_{i}(t)=\sum_{j=1}^{N} \sigma_{i j} e^{\lambda_{j} t} \quad \forall i, j=1,2, \ldots, N,
$$

where $\sigma_{i j}=u_{i j} y_{0_{j}}$ indicates the size of mode $j$ 's contribution. Note that $\sigma_{i j}$ is fault-dependent since $y_{0}$ depends on the disturbance. Hence, mode dominance measure will be defined by adding the magnitudes of mode j's contributions to the oscillations of all the generator states [21]

$$
M D_{j}=\sum_{j=1}^{N}\left|\sigma_{i j}\right| \quad \forall i, j=1,2, \ldots, N .
$$

Thus, $M D_{j}$ measures the dominance of mode $j$ in the overall system. Therefore, for a given disturbance, the mode with the largest $M D$ is the dominant mode. This criterion will be used in the later sections to identify the dominant mode in the Nigerian power system, given faults in some strategic locations. In the following section, the Nigerian 48-bus power system and the model adopted for the simulations are described.

\section{The Nigerian 48-Bus Power System}

The single-line diagram of the Nigerian 48-bus power system is shown in Fig. 1. The network diagram and the load flow data were adapted from [22]. However, the buses have been renumbered to have the generator buses appear first. This choice offers some convenience in computer programming. The network is predominantly on $330 \mathrm{kV}$ but, some segments of $132 \mathrm{kV}$ networks are also added to include generators on the $132 \mathrm{kV}$ side, thanks to the per-unit system that allows considering branches of different voltage levels.

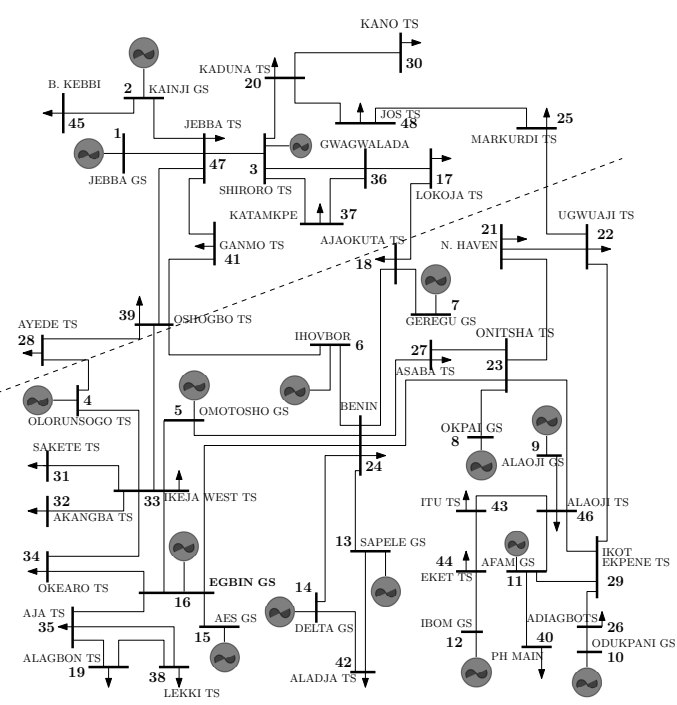

Fig. 1. Single-line diagram of Nigeria 48-bus power system

The network comprises 16 generators and 79 transmission lines. Many factors are capable of triggering severe oscillations in the Nigerian power system. The hydroelectric plants are located mainly at Kainji, Jebba, and Shiroro; this accounts for about $30 \%$ of the total generation. Kainji and Jebba are located on the River Niger, which has regular floods, but the Shiroro Hydroelectric Power Station is situated on the Kaduna River. The southern natural gas-fired thermal power plants are vulnerable to gas pipeline vandalism [23]. Some parts of the existing Transmission Company of Nigeria's $330 \mathrm{kV}$ and 132 $\mathrm{kV}$ networks are inadequate to cope with the demand even under normal steady-state conditions. The distribution network infrastructure suffers from overloaded transformers requiring regular load shedding, overloaded overhead line conductors, 
and an insufficient number of $132 / 33 \mathrm{kV}$ substations. The shortfall in generation availability in Nigeria has resulted in load shedding being the norm and the operation of the grid outside its acceptable frequency control policy. System collapses have been averted because of the authorised installation of under frequency relays in some feeders. It is clear that the generators are unevenly distributed, with the three hydro generators (Jebba GS, Kainji GS, and Shiroro GS) located in the far north and the rest gas-fired in the south. The above arrangement presents the network as a 2-area power system where the northern generators form Area 1 and the southern generators, Area 2. These two areas are connected through long transmission lines. The dynamic data for the generator was obtained from [24].

\section{A. Power system model}

The model used is the so-called classical model represented by 13$]-16$ with the assumptions [25]. Though simple, the model is sufficient for the study of electromechanical modes. Note that irrespective of the model used, the nature of electromechanical oscillations remains the same [26].

$$
\begin{aligned}
\dot{\omega}_{i} & =\frac{1}{M}{ }_{i}\left[P_{m_{i}}-P_{e_{i}}-D_{i}\left(\omega_{i}-1\right)\right] \\
\dot{\delta}_{i} & =\omega_{s}\left(\omega_{i}-1\right) \\
P_{e_{i}} & =E_{i}^{2} G_{i i}+\sum_{j=1, j \neq i}^{N} E_{i} E_{k}\left[G_{i j} \cos \delta_{i j}+B_{i j} \sin \delta_{i j}\right] \\
\delta_{i j} & =\delta_{i}-\delta_{j},
\end{aligned}
$$

where $E_{i}$ is internal bus voltage of generator $i, M_{i}$, inertia constant of generator $i, P_{m_{i}}$, mechanical power input of generator $i, P_{e_{i}}$, electrical power of generator $i, G_{i i}$, driving point conductance of node $i, G_{i j}+j B_{i j}$, the transfer admittance in the system reduced to the internal nodes between generators $i$ and $j, \omega_{i}$, rotor speed of generator $i, \omega_{s}$, synchronous speed, $\delta_{i}$, rotor angle of generator $\mathrm{i}, \omega_{i}$, rotor speed of generator $i, \omega_{s}$, synchronous speed, $D_{i}$, damping coefficient of generator $i$. We added a slight uniform damping $(D=0.3)$ to enable one see the stability of the eigenvalues. Moreover, interest is always on the improvement of poorly damped oscillations. Furthermore, we have adopted the usual assumption that the power system runs in a balanced state; nevertheless, the small-signal analysis may be performed in an unbalanced power system [27].

The model described above was implemented in a MATLAB $^{\circledR}$ environment with the algorithm developed by the authors. In the following section, the simulations and the discussions of the results are systematically presented.

\section{Simulation Results and Discussions}

\section{A. Participation factor analysis and grouping of generators}

Firstly, the power system model (i.e., 13 - 16) is linearised to obtain the state matrix $\mathbf{A}$, the eigenvalues, and eigenvectors as discussed in Section III Secondly, the linear participation factors for each mode were computed using (9). Note that an eigenvalue can loosely be referred to as a mode since it defines a characteristic frequency of oscillation. Table $\mathbb{1}$ lists all the electromechanical modes in the Nigerian 48-bus power system, along with the most participating generators to the modes. The third column of the table contains the frequencies of these modes in Hertz. The participating generators are arranged in descending order of magnitude in each row, where the bold font indicates the highest participating generator.

The three slowest modes from the table have frequencies, $1 \mathrm{~Hz}, 1.14 \mathrm{~Hz}$ and $1.37 \mathrm{~Hz}$ and are approximately the same as ones identified in [13] for $90 \%$ loading. The majority of the studies will concentrate on these three modes, which are regarded as critical modes. The participation factor quantifies the contributions of modes in the different generators. It also indicates the likely generators responsible for the various oscillations. For instance, from Table I], one can see that a fault that affects Afam GS is likely to excite the $1-\mathrm{Hz}$ oscillation. Similarly, disturbances that affect Delta GS and Kainji GS will likely excite oscillations $1.14 \mathrm{~Hz}$ and $1.37 \mathrm{~Hz}$, respectively, since these generators have maximum participation in these oscillations. This information implies that if the $1-\mathrm{Hz}$ oscillation, for example, is to be controlled by PSS, the PSS should be sited closer to the Afam GS generator. Locating it very far from Afam GS may lead to poor performance.

\section{B. The generator swinging patterns - mode shapes}

The mode shapes show the swinging patterns of the different generators when the modes are excited. The right eigenvectors give information on the shape of the oscillation. Thus, a mode shape is a plot of the right eigenvector for the corresponding eigenvalue. The mode shapes for the three critical modes are depicted in Figs. 2a-f. For each mode, two different plots are used to describe the shape for clarity. For example, the mode shape of $1-\mathrm{Hz}$ oscillation is represented by Fig. 2 a (compass plot) and Fig. 2p (polar plot). The compass plot helps to consider the angles of the generator groups, while the polar plots help to identify the magnitude of each generator's swing. According to the figure, the $1-\mathrm{Hz}$ oscillation involves all of the system's generators. All generators in the north (Area 1) with some generators in the south (Area 2) swing together, and the combination swings in $180^{\circ}$ phase opposition with the rest generators in area 2 . This mode must be properly monitored because when it is dominant, all the generators are affected, and if not suitably damped, many generators will lose synchronism. The other two oscillations may be considered as local modes, given that not many generators are significantly involved. Moreover, for $1.14 \mathrm{~Hz}$, one generator (Delta GS) has major participation (see Table I). However, 1.37-Hz oscillation may have a serious inter-area phenomenon, whereby the two areas swing in $180^{\circ}$ phase opposition since the two major participating generators are located one in each area. This behaviour is more likely to occur if a fault occurs on a lengthy line connecting the two regions, as in this research.

\section{Validating with time-domain simulations}

The analyses presented so far are under steady-state conditions. To confirm those oscillations, they must be observed in the system dynamics when they are excited. To see the oscillation patterns described above, each of the modes must 
TABLE I

THE SYSTEM EIGENVALUES

\begin{tabular}{cccl}
\hline Mode $(\#)$ & Eigenvalue & Frequency $(\mathrm{Hz})$ & Participating Generators \\
\hline$\lambda_{1,2}(1)$ & $-0.005 \pm \mathrm{j} 14.856$ & 2.36 & Shiroro GS \\
$\lambda_{3,4}(2)$ & $-0.004 \pm \mathrm{j} 12.817$ & 2.04 & Jebba GS \& Kainji GS \\
$\lambda_{5,6}(3)$ & $-0.002 \pm \mathrm{j} 6.308$ & 1.00 & Afam GS, Alaoji GS, Odukpani GS \& Delta GS \\
$\lambda_{7,8}(4)$ & $-0.002 \pm \mathrm{j} 7.166$ & 1.14 & Delta GS \\
$\lambda_{9,10}(5)$ & $-0.003 \pm \mathrm{j} 8.631$ & 1.37 & Kainji GS, AES GS, Jebba GS \& Egbin GS \\
$\lambda_{11,12}(6)$ & $-0.002 \pm \mathrm{j} 11.735$ & 1.87 & Egbin GS \& AES GS \\
$\lambda_{13,14}(7)$ & $-0.004 \pm \mathrm{j} 11.478$ & 1.82 & Ihovbor GS \\
$\lambda_{15,16}(8)$ & $-0.004 \pm \mathrm{j} 9.039$ & 1.44 & Odukpani GS \&Alaoji GS \\
$\lambda_{17,18}(9)$ & $-0.003 \pm \mathrm{j} 9.702$ & 1.54 & AES GS,Geregu GS, Olorunsogo GS \& Sapelle GS \\
$\lambda_{19,20}(10)$ & $-0.003 \pm \mathrm{j} 9.390$ & 1.50 & Alaoji GS, Afam GS \& Odukpani GS \\
$\lambda_{21,22}(11)$ & $-0.003 \pm \mathrm{j} 9.470$ & 1.51 & Olorunsogo GS \& Geregu GS \\
$\lambda_{23,24}(12)$ & $-0.004 \pm \mathrm{j} 10.773$ & 1.72 & Omotosho GS \& Sapelle GS \\
$\lambda_{25,26}(13)$ & $-0.004 \pm \mathrm{j} 10.643$ & 1.70 & Okpai Gs, Sapelle GS, Geregu Gs \& Omotosho GS \\
$\lambda_{27,28}(14)$ & $-0.005 \pm \mathrm{j} 10.614$ & 1.69 & Geregu Gs \& Okpai GS \\
$\lambda_{29,30}(15)$ & $-0.005 \pm \mathrm{j} 10.486$ & 1.67 & Ibom GS \\
$\lambda_{31}(16)$ & -0.006 & 0.00 & All Generators
\end{tabular}

be excited separately. It is indeed challenging to excite exactly one mode in an interconnected system in practice. A disturbance can, however, be generated in such a way that the desired mode becomes dominant. According to the participation factor analysis, a fault at the most participating generator will likely excite the desired mode. As we shall see later, this is not always the case in the analysis. As an alternative, the system can be initialised with a linearly-scaled eigenvector corresponding to the desired mode. With this technique, the responses for the three critical modes excited are shown in Figs. 3 a-c. In Fig. 3 a, generators Alaoji GS, Odukpani GS, Afam GS, and Ibom GS swing against the rest of the generators with a frequency of about $1 \mathrm{~Hz}$. This swing pattern is consistent with Fig. $2 \mathrm{a}-\mathrm{b}$, which confirms the excitation of $1-\mathrm{Hz}$ mode. In Fig. 3 p, a large oscillation (i.e., relative to others) of the Delta GS generator is observed with a frequency of about $1.13 \mathrm{~Hz}$. This generator swings principally against Jebba GS, Kainji GS, Shiroro GS, AES GS, and Olorunsogo GS. The rest are unclear but diminished. The swing pattern is coherent with the observation in Fig. 22 $\mathrm{d}$, confirming the presence and excitation of the $1.14-\mathrm{Hz}$ mode. Similarly, Fig. 3r shows principally the oscillation of Kainji GS and Jebba GS (Area 1) against AES GS (Area 2) at a frequency of about $1.35 \mathrm{~Hz}$. This pattern corresponds to the excitation of the $1.37-\mathrm{Hz}$ mode as verified by Fig. 2 $2-$ f. Fig. 4 is used to evoke the importance of estimating the dominant mode by simulating a three-phase fault at Bus 14 (where generator Delta GS is connected) cleared after 0.03 seconds. From the participation factor analysis, we expect to excite oscillation mode $1.14 \mathrm{~Hz}$ (see Table T).

It is clear from Fig. 4 that oscillation $1.14 \mathrm{~Hz}$ is not remarkably excited. At least, one will expect the Delta GS to swing against other generators following the mode shape in Figs. 2 2 -d. Instead, we see all generators swinging in the same direction. Moreover, the oscillation frequency observed is about $1.84 \mathrm{~Hz}$. The $1.14 \mathrm{~Hz}$ is not observed for this disturbance because it is not dominant, despite having Delta GS as the highest participating generator to this oscillation.
This observation underscores the importance of identifying the dominant mode for a particular disturbance. The mode dominance measure presented in the next section will better explain the above phenomenon.

\section{Identification of the dominant modes}

Faults were created in some strategic locations of the system to investigate mode dominance. Bus 18 , Bus 22 , Bus 39 , Bus 2, Bus 11, and Bus 14 were considered potential fault locations. Buses 18, 22, and 39 were chosen to anticipate the interarea phenomenon because they connect the two network areas. Buses 2, 11, and 14 were selected to excite the critical modes because the generators connected to these buses participate in them the most. In all cases, after the fault is cleared, (12) is used to compute the mode dominance for the rotor angle states. The mode dominance calculated for all cases are listed in Table 1 The bold font indicates the dominant mode. The results for the fault at Bus 2 show that the $1.37-\mathrm{Hz}$ mode has the highest normalized $M D$ value (i.e.,1), making it dominant. The $1 \mathrm{~Hz}$ and 1.14- $\mathrm{Hz}$ modes are next, with $M D$ values of 0.2191 and 0.2959 , respectively. The observation is expected because Kainji GS, which contributes the most to the $1.37-\mathrm{Hz}$ oscillation, is connected to Bus 2. For fault at Bus 11 , the $1-\mathrm{Hz}$ oscillation mode is dominant, with a normalized $M D$ value of 1 . The rest modes are relatively small. This observation also agrees with the participation factor analysis, which indicates that Afam GS has the highest participation in the $1-\mathrm{Hz}$ oscillation. For fault at Bus 14, we see that several modes are significantly excited. Two critical modes $(1 \mathrm{~Hz}$ and $1.14 \mathrm{~Hz})$ are remarkably excited, as are other local modes such as $1.54 \mathrm{~Hz}, 1.51 \mathrm{~Hz}$, and $1.70 \mathrm{~Hz}$. The $1.87-\mathrm{Hz}$ mode is dominant, with a $M D$ value of 1 , rather than the $1.14-\mathrm{Hz}$ mode predicted by the participation factor analysis. It is noted from Table I that the Delta GS generator connected to Bus 14 does not appear to participate significantly in any of the excited modes except the $1.14-\mathrm{Hz}$ oscillation. It implies a fault-dependent measure is required to uncover the latent information that the steady-state analysis 
TABLE II

MODE DOMINANCE (MD)* MEASURES FOR VARIOUS DISTURBANCES

\begin{tabular}{ccccccccc}
\hline Mode $(\#)$ & Eigenvalues & Frequency $(\mathrm{Hz})$ & \multicolumn{7}{c}{ Mode dominance $(\mathrm{MD})$} \\
\hline & & & Bus 2 & Bus 11 & Bus 14 & Bus 39 & Bus 18 & Bus 22 \\
$\lambda_{1,2}(1)$ & $-0.005 \pm \mathrm{j} 14.8560$ & 2.36 & 0.0236 & 0.0326 & 0.1001 & 0.2094 & 0.0146 & 0.1651 \\
$\lambda_{3,4}(2)$ & $-0.004 \pm \mathrm{j} 12.8167$ & 2.04 & 0.2063 & 0.0163 & 0.0647 & 0.2485 & 0.0055 & 0.0962 \\
$\lambda_{5,6}(3)$ & $-0.002 \pm \mathrm{j} 6.3083$ & 1.00 & 0.2191 & 1.0000 & 0.6225 & 0.4095 & 0.2241 & 0.3706 \\
$\lambda_{7,8}(4)$ & $-0.002 \pm \mathrm{j} 7.1664$ & 1.14 & 0.2959 & 0.0032 & 0.7015 & 0.4421 & 0.1009 & 0.0592 \\
$\lambda_{9,10}(5)$ & $-0.003 \pm \mathrm{j} 8.6308$ & 1.37 & 1.0000 & 0.0119 & 0.1834 & 1.0000 & 0.0307 & 0.3829 \\
$\lambda_{11,12}(6)$ & $-0.002 \pm \mathrm{j} 11.7352$ & 1.87 & 0.0875 & 0.1230 & 1.0000 & 0.5708 & 0.2085 & 0.5205 \\
$\lambda_{13,14}(7)$ & $-0.004 \pm \mathrm{j} 11.4776$ & 1.82 & 0.0659 & 0.0524 & 0.3012 & 0.0349 & 0.3149 & 0.2052 \\
$\lambda_{15,16}(8)$ & $-0.004 \pm \mathrm{j} 9.0386$ & 1.44 & 0.0728 & 0.0813 & 0.1219 & 0.0478 & 0.1462 & 0.1225 \\
$\lambda_{17,18}(9)$ & $-0.003 \pm \mathrm{j} 9.7020$ & 1.54 & 0.2052 & 0.0902 & 0.8666 & 0.0621 & 1.0000 & 0.6055 \\
$\lambda_{19,20}(10)$ & $-0.003 \pm \mathrm{j} 9.3902$ & 1.50 & 0.0022 & 0.0080 & 0.1121 & 0.0211 & 0.0918 & 0.1227 \\
$\lambda_{21,22}(11)$ & $-0.003 \pm \mathrm{j} 9.4704$ & 1.51 & 0.0816 & 0.0916 & 0.7652 & 0.2146 & 0.7357 & 0.5647 \\
$\lambda_{23,24}(12)$ & $-0.004 \pm \mathrm{j} 10.7728$ & 1.72 & 0.0064 & 0.0068 & 0.0923 & 0.0140 & 0.0434 & 0.0317 \\
$\lambda_{25,26}(13)$ & $-0.004 \pm \mathrm{j} 10.6430$ & 1.70 & 0.0126 & 0.2103 & 0.7717 & 0.1510 & 0.6972 & 1.0000 \\
$\lambda_{27,28}(14)$ & $-0.005 \pm \mathrm{j} 10.6144$ & 1.69 & 0.0427 & 0.1041 & 0.3330 & 0.0133 & 0.9506 & 0.4560 \\
$\lambda_{29,30}(15)$ & $-0.005 \pm \mathrm{j} 10.4864$ & 1.67 & 0.0113 & 0.1770 & 0.0986 & 0.0203 & 0.1355 & 0.035
\end{tabular}

does not reveal. The activities of other modes on Delta GS states become clear when Delta GS is disturbed. If fault at Bus 14 excites significantly several modes, it is likely these modes are interacting. In that case, a specific control design is needed to avert the influence of modal interaction. The adverse implications of nonlinear modal interaction on the dynamic performance of the power system are documented in [17]. The other fault locations link the two areas of the system. For fault at buses 18 and 22, it can be marked that the critical modes are not significantly excited compared to the dominant modes. Many local modes, on the other hand, are remarkably excited. The connection between the two areas via Bus 39 is especially compelling. In that case, the $1.37-\mathrm{Hz}$ mode becomes dominant with significant excitation of the other two critical modes. Another mode also significantly excited is the 1.87$\mathrm{Hz}$ mode. Just as Bus 14, another vulnerable area for fault is Bus 39. All the critical modes are energized, and the inter-area phenomenon occurs. A large power flow between the two areas through Bus 39 will likely excite these slow modes. Once more, the simultaneous significant excitation of the critical modes motivates the investigation of potential nonlinear interactions of these modes.

\section{E. Investigating potential for nonlinear modal interaction}

The detailed techniques for confirming modal interaction in an interconnected system have been documented in [17][19]. Those techniques cannot be treated rigorously within the framework of the present paper. This section gives helpful insights into the modal interaction possibilities in the Nigerian power system. The nonlinear participation factors are computed for the most concerned generators. For this, the second-order terms in the Taylor expansion are considered (details omitted) to implement (10). With such modelling, the nonlinear participation factors will have 465 entries for each generator state. The first 15 largest entries of the nonlinear participation factors are extracted. If the eigenvalue combinations in the 15 entries include these critical modes, the associated modes will most likely interact depending on the nature of the disturbance. The concerned generators are Kainji GS (for 1.37 Hz), Delta GS (for $1.14 \mathrm{~Hz}$ ), and Afam GS (for $1 \mathrm{~Hz}$ ).

The first 15 entries for the nonlinear participation factors for the three generators are shown in Figs $5 \mathrm{a}-\mathrm{c}$.

The Fig $5 \mathrm{a}$, for example, should be interpreted as follows: apart from the contribution of the single eigenvalues to the oscillation of Kainji GS, the combinations $\lambda_{3}+\lambda_{4}, \lambda_{9}+\lambda_{10}$, $\lambda_{3}+\lambda_{10} \ldots$, also participate and the bars are magnitudes of their participation. Combining Fig 5 and Table 1 it can be seen that when the $1.37 \mathrm{~Hz}$ is significantly excited, it may lead to nonlinear interactions. This can be seen from Fig $5 \mathrm{a}$, where the first 15 entries are dominated by the eigenvalue combinations attributed to the critical modes. This observation explains why $1-$ and $1.14-\mathrm{Hz}$ oscillations seem to be the succeeding significantly excited modes whenever 1.37 $\mathrm{Hz}$ mode is excited (examples, for fault at buses 2 and 39 in Table (I). The excitation of $1-\mathrm{Hz}$ oscillation may not lead to significant nonlinear interactions among the critical modes. This can be seen from Fig $5 \mathrm{~b}$, which does not convincingly show the combination of these critical modes in the first 15 largest entries of the nonlinear participation factors. Instead, it shows the interactions of the $1-\mathrm{Hz}$ mode with other local modes of high frequencies. This observation is also supported by Table [I], which shows no significant excitation of other modes when $1-\mathrm{Hz}$ oscillation is excited. Note that the $1-\mathrm{Hz}$ mode being very slow, may self-interact (e.g., $\lambda-5,6+\lambda_{5,6}$ ) if the disturbance favours such. Finally, applying the same interpretation to Fig 5c, it is clear that the excitation of 1.14$\mathrm{Hz}$ oscillation may lead to nonlinear interaction since the first 15 largest entries of the nonlinear participation factors are dominated by the combinations of these critical modes. This argument is also corroborated by Table II] where a significant excitation of the $1.14-\mathrm{Hz}$ mode was also accompanied by excitation of $1-\mathrm{Hz}$ mode and several others. These observations strongly suggest the presence of nonlinear interactions among the electromechanical modes in the Nigeria power system.

To probe deeper into the interaction phenomenon, we computed the fast Fourier transform (FFT) for the rotor angles of generators, Kainji GS, Afam GS, and Delta GS for each 


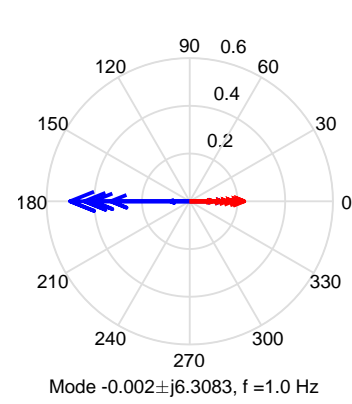

(a)

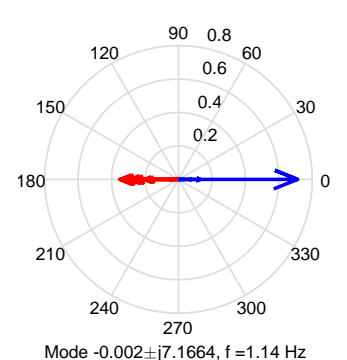

(c)

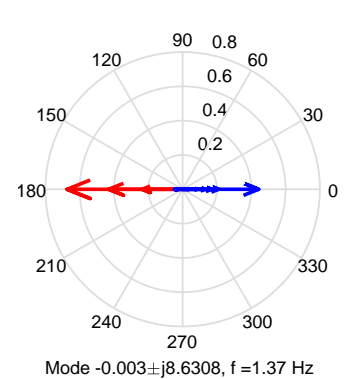

(e)

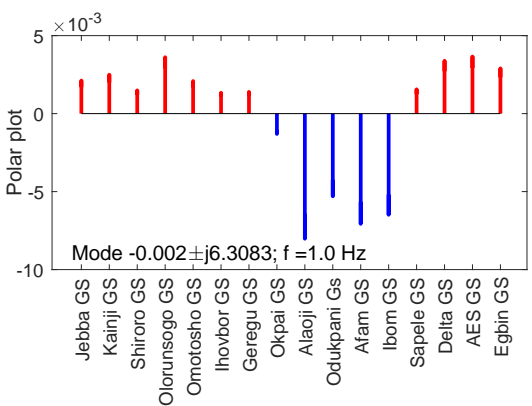

(b)

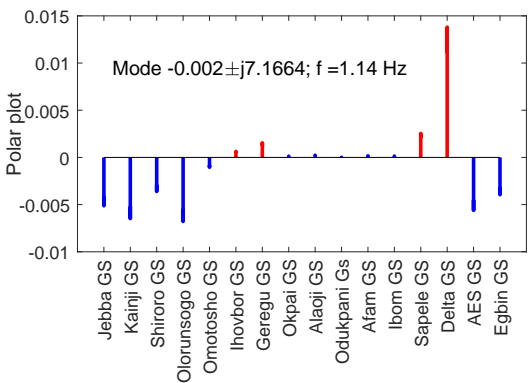

(d)

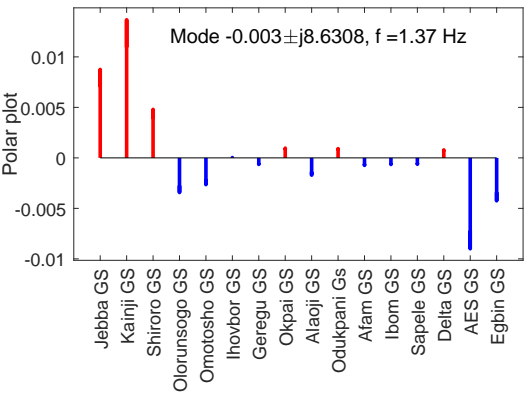

(f)
Fig. 2. Mode shapes: (a)-(b) $1-\mathrm{Hz}$ mode; (c)-(d) $1.14-\mathrm{Hz}$ mode; (e)-(f) 1.37- $\mathrm{Hz}$ mode.

fault location (i.e., at buses 14, 11, and 2). All faults were cleared after 0.08 seconds. For the fault at Bus 14 (Delta GS bus), the FFT for Kainji GS, Afam GS, and Delta GS is shown in Figs. 6a-c, respectively. It will be observed that in the case of Kainji GS, there exist significant peaks at frequencies not found in Table I. For instance, $1.33 \mathrm{~Hz}$ and $2.4 \mathrm{~Hz}$ can be assumed to approximately corresponding to the linear frequencies $1.37 \mathrm{~Hz}$ and $2.36 \mathrm{~Hz}$, but the frequency $2.71 \mathrm{~Hz}$ that has a significant peak does not exist among the linear modes in Table II This frequency is likely the self interaction of mode $1.37 \mathrm{~Hz}$ (i.e, $1.37+1.37 \approx 2.74 \mathrm{~Hz}$ ). It means that a second-order resonance occurs with the 1.37$\mathrm{Hz}$ mode. Note that Fig $5 \mathrm{a}$ contains several combinations with eigenvalue $\lambda_{9,10}$ (i.e. $1.37-\mathrm{Hz}$ mode). However, since the 1.54 $\mathrm{Hz}$ mode is also significantly excited in this case, the frequency may also be a result of the combination $\lambda_{7,8}+\lambda_{17,18}$ (i.e., $1.14+1.54=2.6 \mathrm{~Hz})$. Fig $5 \mathrm{k}$ also supports this observation as it shows those combinations. This observation implies the dynamics of Kainji GS will be impacted not only by the linear modes but also by the modal interactions. For the

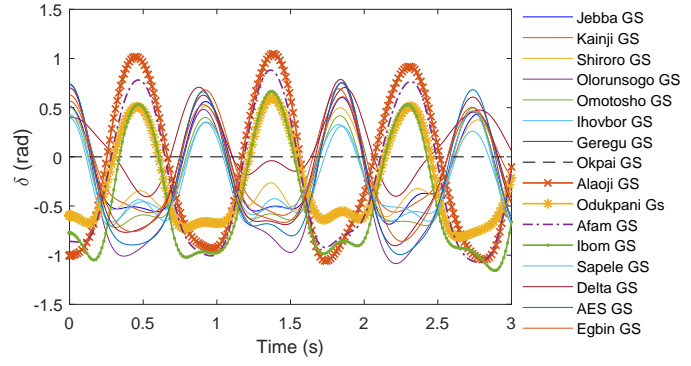

(a)

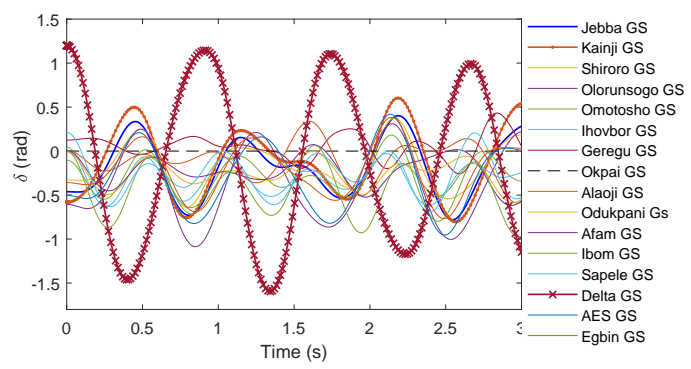

(b)

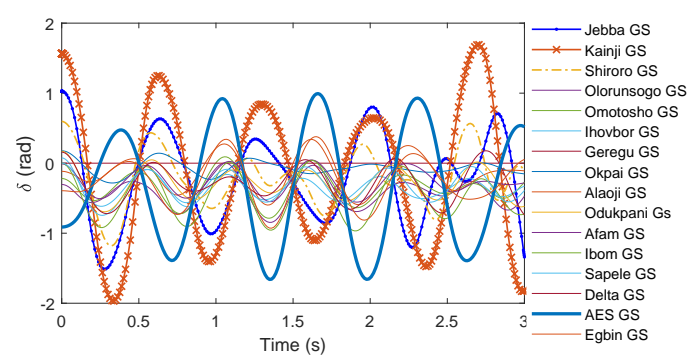

(c)

Fig. 3. Mode excitation: (a) $1-\mathrm{Hz}$ mode; (b) $1.14-\mathrm{Hz}$ mode; (c) $1.37-\mathrm{Hz}$ mode.

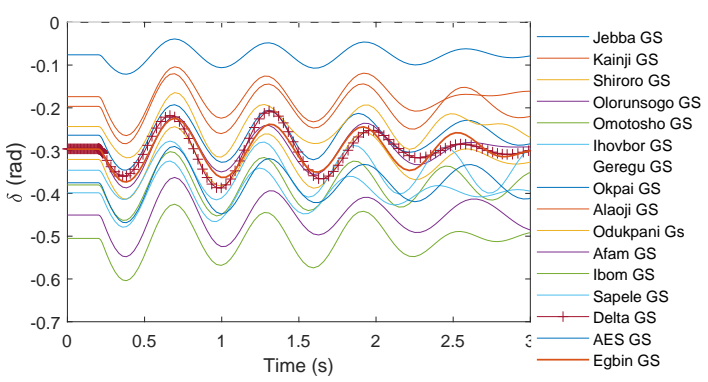

(a)

Fig. 4. Expected 1.14- $\mathrm{Hz}$ mode not dominant in the response

other two generators (Afam GS and Delta GS), all the peaks typically correspond to the linear modes in Table I So, they are unimpacted by the modal interaction.

For the fault at Bus 11 (Afam GS bus), the FFT for Kainji GS, Afam GS, and Delta GS is shown in Figs. $7 \mathrm{a}-\mathrm{c}$ respectively. Once more, the peaks for the case of Kainji GS are remarkable. While the $2.23 \mathrm{~Hz}$ and $2.1 \mathrm{~Hz}$ frequencies appearing in Fig. 7 7 may be assumed to correspond to the linear modes $2.36 \mathrm{~Hz}$ and $2.04 \mathrm{~Hz}$ respectively (see Table I), it is unlikely that the $2.1 \mathrm{~Hz}$ is a linear mode. It makes sense to identify this frequency as a self-combination of the 


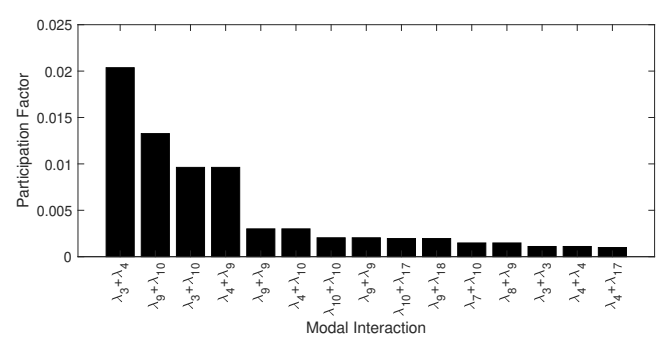

(a)

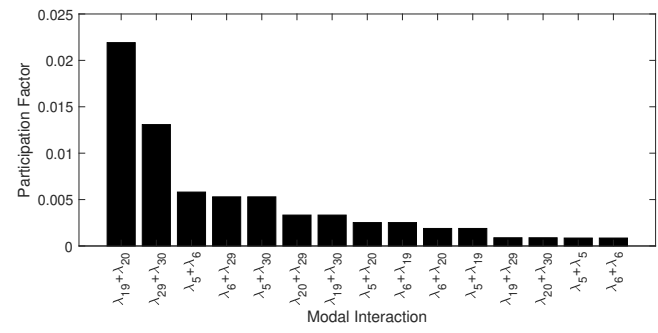

(b)

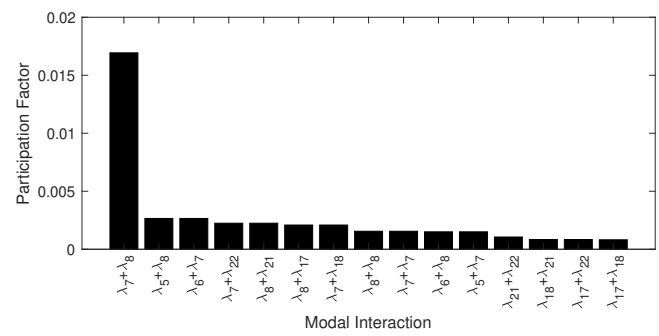

(c)

Fig. 5. Nonlinear participation factors: (a) Kainji GS, (b) Afam GS, and (c) Delta GS.

$1-\mathrm{Hz}$ mode (i.e, $1.0+1.0 \approx 2.1 \mathrm{~Hz}$ ). Note that in Fig $5 \mathrm{p}$ there exist several combinations of eigenvalues $\lambda_{5,6}$ (i.e., 1 $\mathrm{Hz}$ mode). Therefore, this $2.1 \mathrm{~Hz}$ is more likely a result of the combination $\lambda_{5,6}+\lambda_{5,6}$. Moreover, the $1-\mathrm{Hz}$ mode is dominant in this case and is most associated with Delta GS. It is remarked that the peaks in the other two generators typically correspond to the linear modes in Table I]

Finally, for a fault at Bus 2 (Kainji GS bus), the FFT for Kainji GS, Afam GS, and Delta GS is shown in Fig. 8p-c respectively. For Kainji GS, there are significant peaks whose corresponding frequencies $(2.69 \mathrm{~Hz}$ and $2.89 \mathrm{~Hz})$ are unknown to Table II The credible sources of these frequencies, in this case, are complex to identify. The $2.69 \mathrm{~Hz}$ may come from self-interaction of the $1.37-\mathrm{Hz}$ mode while the $2.89 \mathrm{~Hz}$ is likely a result of the combination $\lambda_{9,10}+\lambda_{17,18}$ (1.e, $1.37 \mathrm{~Hz}+$ $1.54 \mathrm{~Hz}$ ). This interpretation agrees with Fig $5 \mathrm{a}$, which shows those combinations. However, those frequencies may also come from third-order interactions. What should be noted here is that there undoubtedly exist nonlinear modal interactions, and the troubled generator in all cases is the Kainji GS, even when faults are located far from it. The analyses confirm the presence of nonlinear modal interaction among the critical modes. However, the practical certainty of the mode combinations that typically led to those unknown frequencies requires further investigation by more robust methods like [18].

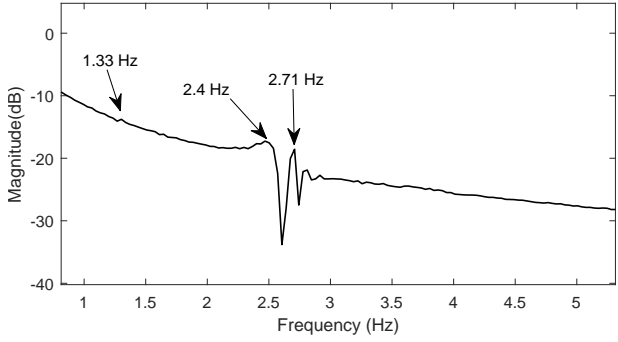

(a)

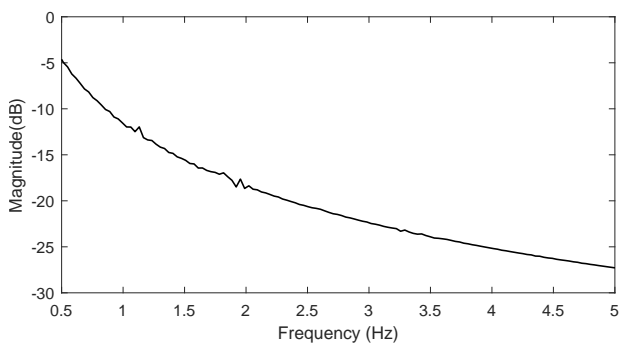

(b)

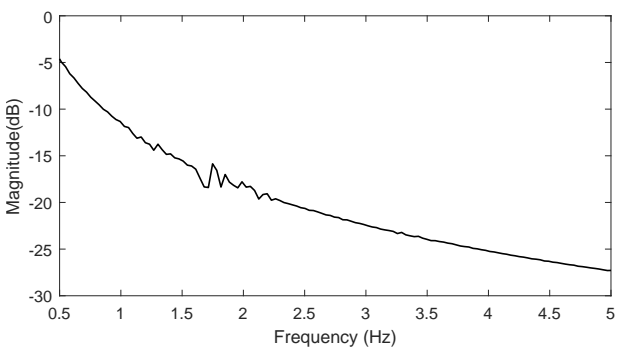

(c)

Fig. 6. FFT of $\delta$ : (a) Kainji GS; (b) Afam GS; (c) Delta GS.

\section{F. Practical implications of the modal interactions}

1) The modal interaction depends on the stress in the system, i.e., the severity of a disturbance or the extent of system loading. From the analyses performed, it seems that the Kainji GS generator is highly loaded. It is plausible, especially since its dynamics deteriorates irrespective of the fault location. Moreover, the very recent study [28] tends to suggest the entire power system is highly loaded with instability warning existing already at $100 \mathrm{MW}$ load increase.

2) The Kainji GS seems to be weakly connected to the entire system. The transmission lines connected to the Kainji GS bus need to be reinforced to address this issue.

3) This study confirms the dominant position and importance of Kainji GS for electricity generation in Nigeria (and the electricity supplied to the neighbouring Niger Republic). The importance of Kainji GS emphasizes the need for the government to address the causes of the River Niger's occasional droughts, which reduces the Kainji's output power.

4) When nonlinear modal interactions become strong, the linear control techniques may give deceptive results and poor performance. Nonlinear control should be incorporated in the Nigerian power systems, especially for 


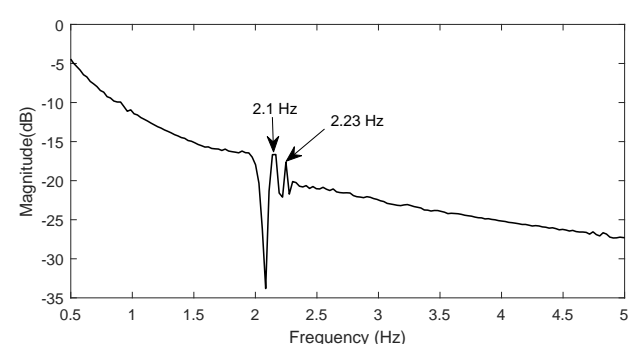

(a)

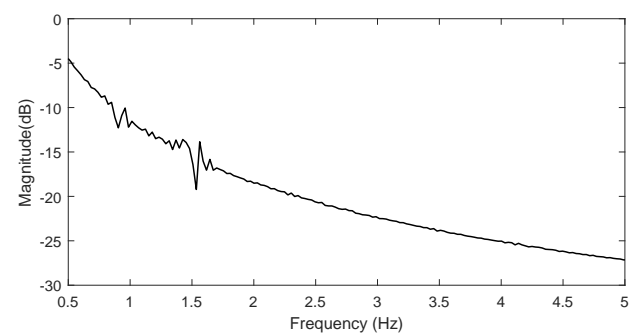

(b)

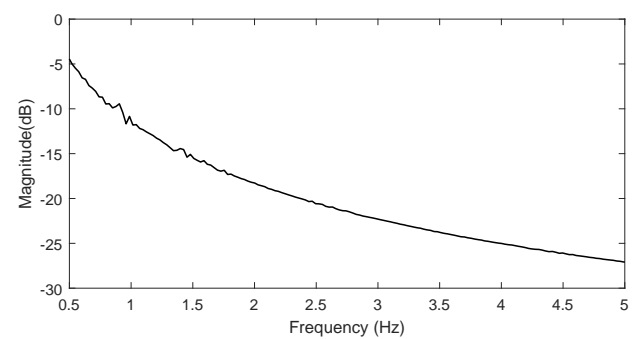

(c)

Fig. 7. FFT of $\delta$ : (a) Kainji GS; (b) Afam GS; (c) Delta GS.

Kainji GS, Delta GS, and Afam GS.

\section{CONCLUSIONS}

In this paper, a comprehensive study of electromechanical oscillations in the Nigerian 48-bus power system is presented. The electromechanical oscillation modes with the corresponding participating generators have been identified. Among the oscillation modes, the three slowest modes $(1 \mathrm{~Hz}, 1.14 \mathrm{~Hz}$, and $1.37 \mathrm{~Hz}$ ) have been extensively studied with elegant swinging patterns and supporting time-domain simulations. To better understand the dominant modes when disturbances arise, a disturbance-dependent mode dominance measure has been proposed. Furthermore, the nonlinear modal interaction of low-frequency modes is investigated for the first time in the Nigerian power system to the authors' knowledge. The following conclusions can be drawn from the analyses presented:

- Inter-area phenomenon exists in the Nigerian power system, and the responsible generators are Kainji GS, Afam GS, and Delta GS.

- Disruptions to Afam GS cause oscillations involving all of the generators in the network. The operators should adequately protect this generator.

- There exist nonlinear modal interactions among the electromechanical modes in the Nigerian power system.

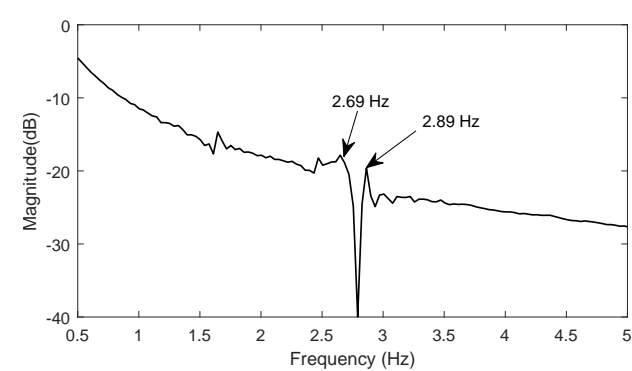

(a)

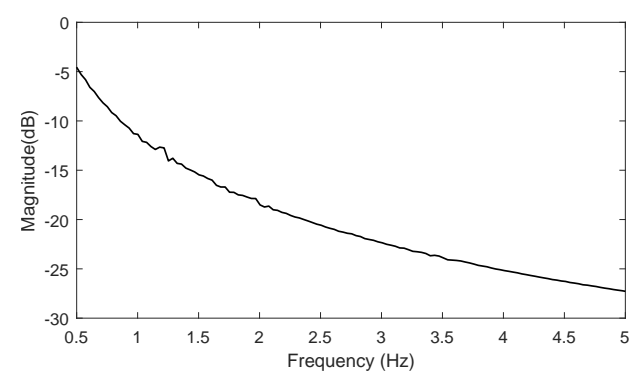

(b)

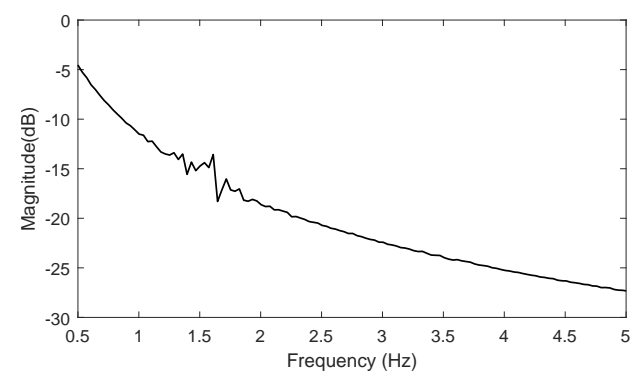

(c)

Fig. 8. FFT of $\delta$ : (a) Kainji GS, (b) Afam GS, and (c) Delta GS.

These interactions are caused mainly by the slow modes $1.37 \mathrm{~Hz}, 1.14 \mathrm{~Hz}$, and $1 \mathrm{~Hz}$.

- The dynamics of the generator at the Kainji power station will be most affected by the nonlinear modal interactions.

- Disruptions to generator Delta GS cause significant excitation of several modes in the system. The control architecture of Delta GS should be given special attention to check its oscillation.

- Disturbances along the lines linking the two areas of the power system through the Oshogbo bus (Bus 39) may trigger serious oscillation. The power flows along these transmission paths need to be adequately controlled and strengthened using FACTS devices.

The following future works should be considered. A detailed generator model should be used for the investigation; this will aid in understanding the extent of the damping of those oscillations. The true exciter and PSS data from the Nigerian power system must be available for this, not the assumed values seen in the literature. A detailed investigation of nonlinear modal interactions among the oscillation modes is recommended. It will be valuable to investigate in the future the impact of the power electronics penetrations on these oscillations due to renewable energy sources. As stated in Section IIII. Areas 
1 and 2 are connected via long transmission lines. It will be gainful to study the impact of line reactance values (i.e., an indication of grid strength) on the system modes.

\section{REFERENCES}

[1] Ghorai, S. and Ray, S., "Revisiting small signal stability analysis techniques in the context of stability study of a two-area multimachine power system," in 2020 IEEE Calcutta Conference (CALCON), 2020, pp. 493-496.

[2] Guan, R., Deng, N., Xue, Y., and Zhang, X., "Small-signal stability analysis of the interactions between voltage source converters and dc current flow controllers," IEEE Open Access Journal of Power and Energy, vol. 7, pp. 2-12, 2020

[3] Li, Y., Shuai, Z., Fang, J., Wu, X., and Shen, Z. J., "Small-signal stability analysis method for hybrid ac-dc systems with multiple dc buses," IEEE Journal on Emerging and Selected Topics in Circuits and Systems, vol. 11, no. 1, pp. 17-27, 2021.

[4] Oti, E. S. and Okoro, O. I, "Stability analysis of static slip-energy recovery drive via eigenvalue method," Nigerian Journal of Technology, vol. 26, no. 2, pp. 13-29, 2007.

[5] Quintero, J., Vittal, V., Heydt, G. T., and Zhang, H., "The impact of increased penetration of converter control-based generators on power system modes of oscillation," IEEE Transactions on Power Systems, vol. 29, no. 5, pp. 2248-2256, 2014.

[6] Bamisile, O., Huang, Q., Ayambire, P., Anane, P. O. K., Abbasoglu, $\mathrm{S}$., and $\mathrm{Hu}, \mathrm{W}$., "Analysis of solar pv and wind power penetration into nigeria electricity system," in 2020 IEEE/IAS 56th Industrial and Commercial Power Systems Technical Conference (I CPS), 2020, pp. $1-5$.

[7] Olusola, B., Ariyo, O., Sandra, O., Emmanuel, O., Gaylord, A., and Qi, H., "Application of deep learning for solar irradiance and solar photovoltaic multi-parameter forecast," Energy Sources, Part A: Recovery, Utilization, and Environmental Effects, 2020.

[8] Aneke, E. and Engla, A, "Enhancing the voltage stability of the nigerian 330kv 48-bus power system network using modal/eigenvalue analysis," International Journal of Engineering Research and Development, vol. 9, no. 7, pp. 31-46, 2019.

[9] Enemuoh, F. O., Onuegbu, J. C., and Anazia, E. A. , "Modal based analysis and evaluation of voltage stability of bulk power system," International Journal of Engineering Research and Development, vol. 6 no. 12, pp. 71-79, 2013.

[10] Ogonjuyigbe, J. K. and Gonoh, B. A., "Small signal stability analysis of a 330kv network: A case study of the nigerian 330kv network." [Online] Available: https://www.academyjsekad.edu.ng/vol0701-18-28-AJSE.pdf

[11] Ariyo, F. K. and Omoigui, M. O. , "Investigation of the damping of electromechanical oscillations using power system stabilizers (pss) in nigerian $330 \mathrm{kv}$ electrical network," Electrical and Electronic Engineering, vol. 2, no. 4, pp. 236-244, 2012.

[12] Ariyo, F. K. and Omoigui, M. O., "Investigation of nigerian $330 \mathrm{kv}$ electrical network with distributed generation penetration - part i: basic analyses," Electrical and Electronic Engineering, vol. 3, no. 2, pp. 4971, 2013.

[13] Omoigui, M. and Ojo, O., "Analysis of the nigerian $330 \mathrm{kv}$ electric power network using an extended heffron-phillips model technique," International Journal on Engineering Applications (IREA), vol. 3, no. 1, pp. 21-35, 2015.
[14] Nwohu, M. N., "Low Frequency Power Oscillation Damping Enhancement and Voltage Improvement Using Unified Power Flow Controller (UPFC) in Multi-Machine Power System," International Journal of Electrical and Power Engineering, vol. 5, no. 4, pp. 174-180, 2011.

[15] Ambafi, J. G., Nwohu, M. N, Ohize, H. O, and Tola, O. J , "International Journal of Engineering and Technology Performance Evaluation of PSS and STATCOM on Oscillation Damping of a North-Central Power Network of Nigeria Grid System," International Journal of Engineering and Technology, vol. 2, no. 2, pp. 209-219, 2012.

[16] Ugwuanyi, N. S., Uma, U. U., and Ekwue, A. O., "Characterisation of Oscillations in Developing Power Systems : The Nigerian Case Study," accepted in 2021 IEEE PES/IAS PowerAfrica August 23-27, 2021

[17] Sanchez-Gasca, J. J., Vittal, V., Gibbard, M. J, Messina, A. R, Vowles, D. J., Liu, S., and Annakkage, U. D., "Inclusion of higher order terms for small-signal (modal) analysis: committee report-task force on assessing the need to include higher order terms for small-signal (modal) analysis," IEEE Transactions on Power Systems, vol. 20, no. 4, pp. 1886-1904, 2005.

[18] Ugwuanyi, N. S., Kestelyn, X., Marinescu, B., and Thomas, O., "Power system nonlinear modal analysis using computationally reduced normal form method," Energies, vol. 13, no. 5, p. 1249, 2020. [Online]. Available: https://www.mdpi.com/1996-1073/13/5/1249

[19] Ugwuanyi, N., "Contributions Towards Positioning Normal Form Method as a Tool for Analysing Future Power Transmission Grid," $\mathrm{PhD}$ Theses, HESAM Université, Jun. 2020. [Online]. Available: https://tel.archives-ouvertes.fr/tel-02949258

[20] Starrett, S.K. and Fouad, A. A., "Nonlinear measures of mode-machine participation [transmission system stability]," IEEE Transactions on Power Systems, vol. 13, no. 2, pp. 389-394, 1998.

[21] Starrett, S. K., "Application of normal forms of vector fields to stressed power systems," Ph.D. dissertation, IOWA State University, 1994.

[22] Nkan, I. E, Okoro, O. I, Awah, C. C., and Akuru, U. B., "Investigating the steady state stability of the nigerian 48-bus systems using facts devices," Nigerian Journal of Technology, vol. 38, no. 3, pp. 732-743, 2019.

[23] Umar, A. T. and Othman, M. S. H., "Causes and consequences of crude oil pipeline vandalism in the niger delta region of nigeria: A confirmatory factor analysis approach," Cogent Economics \& Finance, vol. 5, no. 1, p. 1353199, 2017

[24] FICHTNER, "Nigeria Electricity and Gas Improvement Project Transmission Expansion Plan Development of Power System Master Plan for the Transmission Company of Nigeria Final Report," Transmission company of Nigeria (TCN), Tech. Rep. December, 2017 [Online]. Available: https://tcnpmu.ng/pmu_assets/pmu_files/2018/02/ Final-Report-Text.pdf

[25] Anderson, P. M. and Fouad, A. A., Power system control and stability, 2nd ed. USA: IEEE Press, 2003.

[26] Rogers, G., Modal Analysis of Power Systems. Boston, MA: Springer US, 2000, pp. 31-73.

[27] Verdejo, H., Moreira, P., Kliemann, W., Becker, C., and Delpiano, J., "An analytical model for small signal stability analysis in unbalanced electrical power systems," Applied Sciences, vol. 10, no. 24, 2020. [Online]. Available: https://www.mdpi.com/2076-3417/10/24/8855

[28] Ezeruigbo, E. N, Ekwue, A. O, and Anih, L. U, "Voltage stability analysis of nigerian $330 \mathrm{kv}$ power grid using static p-v plots," Nigerian Journal of Technology, vol. 40, no. 1, pp. 70-80, 2021. 